\title{
Additional Molecular Studies Were Performed
}

National Cancer Institute

\section{Source}

National Cancer Institute. Additional Molecular Studies Were Performed. NCI Thesaurus.

Code C160313.

An indication that additional molecular tests were performed during the study. 